Saudi Journal of Oral and Dental Research

Abbreviated Key Title: Saudi J Oral Dent Res

ISSN 2518-1300 (Print) |ISSN 2518-1297 (Online)

Scholars Middle East Publishers, Dubai, United Arab Emirates

Journal homepage: https://saudijournals.com/sjodr

\title{
A New 3D Strut Plating In Management of Subcondylar Fractures - A Prospective Study
}

Dr. Marbon Joevitson ${ }^{1 *}$, Dr. Annamalai Thangavelu², Dr. Bharathi Kripakaran ${ }^{3}$, Dr.Thiruneelakandan ${ }^{4}$, Dr. Janarthanan ${ }^{5}$, Dr. Eshona Pearl ${ }^{6}$

${ }^{1}$ Senior Lecturer, Department of Oral and Maxillofacial Surgery, Sree Mookambika Institute of Dental Sciences, Kulasekaram, Kanyakumari District, Tamil Nadu, India

${ }^{2,4,5}$ Professor, Department of Oral and Maxillofacial Surgery, Rajah Muthiah Dental College and Hospital, Annamalai University, Chidambaram, Tamil Nadu, India

${ }^{3}$ Senior Lecturer, Tagore Dental College, Rathinamangalam, Chennai, Tamil Nadu, India

${ }^{6}$ Senior Lecturer, Department of Prosthodontics, Sree Mookambika Institute of Dental Sciences, Kulasekaram, Kanyakumari District, Tamil Nadu, India

DOI: $10.36348 /$ sjodr.2020.v05i05.002

| Received: 03.05.2020 | Accepted: 16.05.2020 | Published: 23.05.2020

*Corresponding author: Dr. Marbon Joevitson

\section{Abstract}

Purpose: The purpose of this study is to evaluate the treatment outcomes in patients with Sub-condylar fractures using 3D Strut Osteosynthesis Plates. Patients and methods: Six patients with sub-condylar fractures were selected randomly between the age of 26 to 36years.Treatment protocols included in the study were open reduction and internal fixation using 3D Strut Osteosynthesis Plates. Associated injuries such as Symphysis, Para symphysis, Zygomatic complex fractures were also included in this study. Statistical analysis using Friedman test and Wilcoxon signed-rank test were performed. Results: The results of our study revealed that there was a significant difference in the mouth opening of sub-condylar fracture patients $(\mathrm{P}$-value $<0.004)$. Comparison between preoperative, 2 months and 6 months follow-up for additional fractures, Occlusion, Complications of Sub-condylar fractures were also performed. Preoperative and 2 months follow-up showed significance with $\mathrm{P}$-value $<0.02$. Preoperative and 6months follow-up also showed significant $\mathrm{P}$-value $<0.028$ and 2 months to 6 months follow-up revealed significant $\mathrm{P}$-value $<0.059$. Postoperative radiographic evaluation showed that the osteosynthesis is relatively stable. Conclusion: All the patients treated with the Strut plating system were functionally stable, well rehabilitated and also proved significant statistical analysis. In our study with sample size limitations, the fracture reduction of sub condyle with the new three- dimensional Strut plate showed excellent stability with no displacement and neutralization of the changing strains in the condylar region. Therefore, further studies with a larger sample size can help to re-evaluate the results in further research using the 3D strut Osteosynthesis plating system.

Keywords: Strut plating, Sub-condylar Fractures, Osteosynthesis.

Copyright @ 2020: This is an open-access article distributed under the terms of the Creative Commons Attribution license which permits unrestricted use, distribution, and reproduction in any medium for non-commercial use (NonCommercial, or CC-BY-NC) provided the original author and source are credited.

\section{INTRODUCTION}

Fractures of the mandibular condyle account for 9 to $45 \%$ of all mandibular fractures [1]. Rarely, condylar fractures occur individually connecting with fractures of the para symphysis, body, angle and even the contralateral condyle [2]. Condylar fractures are not a homogeneous entity, but are subdivided by numerous classifications depending upon the area of interest such as intracapsular and extracapsular fractures, the height of the fracture, condylar head \& neck fracture and the sub condylar region [3]. Fracture of the condyle has intolerance compared to the other parts of the mandible due to its structural and restoration factor. Dislocation of the mandible, occlusal dysfunction, TMJ ankylosis, dearrangements are the consequences of the condylar fractures.

Different school of thoughts in the management of mandibular condylar fractures include conservative, functional and surgical. Usually, maxillomandibular fixation (MMF) with closed treatment is chosen by the surgeons, but the open treatment of condylar fractures with rigid internal fixation (RIF) is more effective. Methods for an open reduction of mandibular sub-condylar fractures have changed and diversified enormously in recent years, but still, there is a controversy regarding the optimal treatment with a variety of different plating systems such as intraoral approach and extraoral approach [4]. 
Fixation with very rigid mini plates provides more stability than transosseous wire, although a single mini plate would be adequate if the fragments are aligned properly and functional forces exceed the rigidity of one mini plate, therefore the use of two has been proposed. However, in the condylar neck, the amount of bone is not always adequate to permit placement of 2-3 screws per fragment. To overcome this problem, various plate designs have been put forward. A single L, Y plate, or 3-D plate has been used in the treatment of condylar fractures, which confine to the tensile stress pattern at the condylar neck region [5]. Instead of two plates, a strut-shaped plate can be used. However, for a proper fracture reduction and an easy, less complicated plate application, the extraoral approach is still preferred. Hence, in our study, we approached open reduction and internal fixation using 3D strut plates to determine the treatment modality and postoperative outcomes in sub-condylar fractures.

\section{MATERIALS AND METHODS Study Group}

The study was performed in the Oral and Maxillofacial Surgery department at Rajah Muthiah Dental College and Hospital, Chidambaram, Tamilnadu, which was approved by the Ethical Committee of Institutional review board. Six patients with age ranging between 16 and 26years with subcondylar fractures were selected. Patients with associated fractures were also included in the study. These patients had undergone surgery with open reduction and internal fixation using 3D strut plates. The informed written consent form was obtained before the study from all the patients. Preoperative OPG was taken to evaluate the fracture site which can be seen in fig.1.

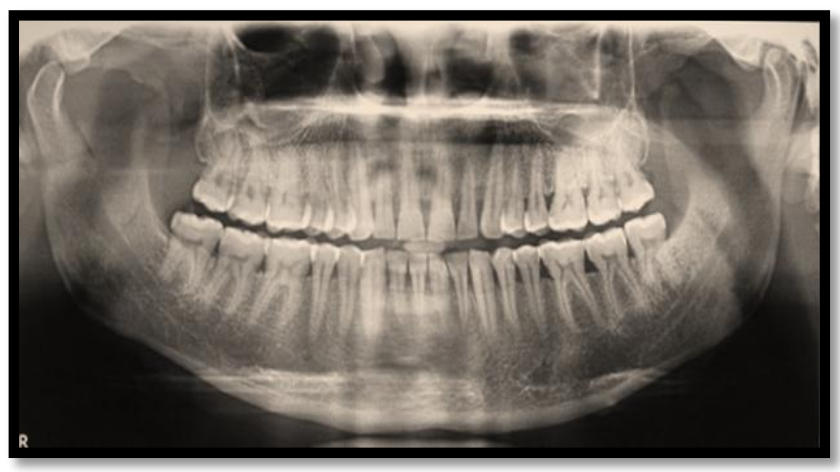

Fig-1: shows Preoperative OPG

\section{Strut Plate}

5-hole strut plate was used in our study for the treatment of sub-condylar fractures. In the strut shaped plate, the longer arm is oriented along the ramus of the mandible, thus the lines of tensile and compressive stress distribution run parallel to the long arm of the plate. The plate also has a shorter arm, which is oriented parallel to the long arm. For placement, the straight 3hole segment should be nearly parallel to the posterior border and aligned with the condylar head. The plate is $2 \mathrm{~mm}$ thick, $28 \mathrm{~mm}$ long and $14 \mathrm{~mm}$ wide. The long arm has 3 longitudinally arranged holes and the shorter arm has 2 holes such that both arms are interconnected by cross metal arms seen in fig. 2 .

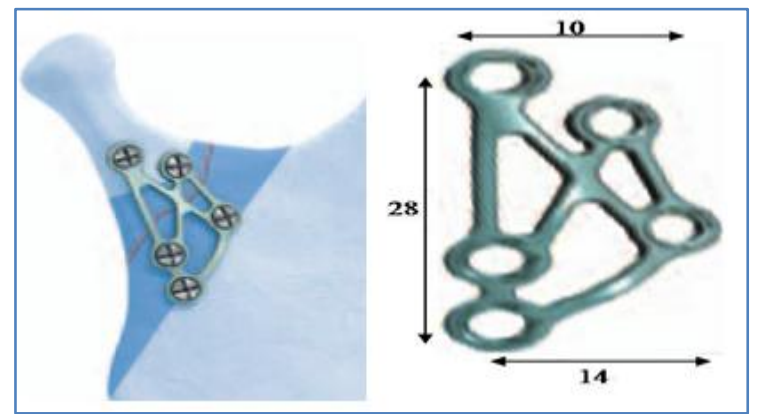

Fig-2: Shows the Dimensions of Strut Plate

\section{Surgical Procedure}

After preparing the surgical sterile field, the zygomatic arch, mandibular condyle and ramus up to the angle were identified and surface markings done. Then, the fracture end is outlined. A standard retromandibular incision is placed (fig.3). The initial incision is carried out through the skin and subcutaneous tissue to the level of the platysma. A fusion of platysma, the superficial musculoaponeurotic system (SMAS) and the parotid capsule is incised in the vertical plane. Blunt dissection begins within the gland in an anteromedial direction towards the posterior border of the mandible. The marginal mandibular branch of the facial nerve is often encountered and may be retracted superiorly or inferiorly depending on its location along with retromandibular tissues. The masseter muscle is stripped from the lateral surface of the mandible using periosteal elevator and retraction is facilitated by inserting a sigmoid retractor into the sigmoid notch. When the bone surface is reached, the periosteum is elevated and the fracture is identified. The reduction was done using Langenbeck retractor placed at the sigmoid notch. Then $2 \mathrm{~mm}$ 5-hole Strut subcondylar plate(titanium) was placed at the fractured site (fig.4) with its long arm parallel to the posterior border of the ramus and with its short arm just below the 
sigmoid notch and stabilized using $2 \times 8 \mathrm{~mm}$ titanium screws (5 in number). All the patients underwent intermaxillary fixation using arch bars. Out of 6 patients, 5 patients had associated fractures, where an existing extraoral chin incision was placed in one patient and an intraoral vestibular approach was done for the remaining 4 cases. Associated Zygomatic complex fracture in one case was managed using fronto-temporal approach. All the patients were given a high dose of antibiotics and steroids. Strict oral hygiene instructions were given to patients.

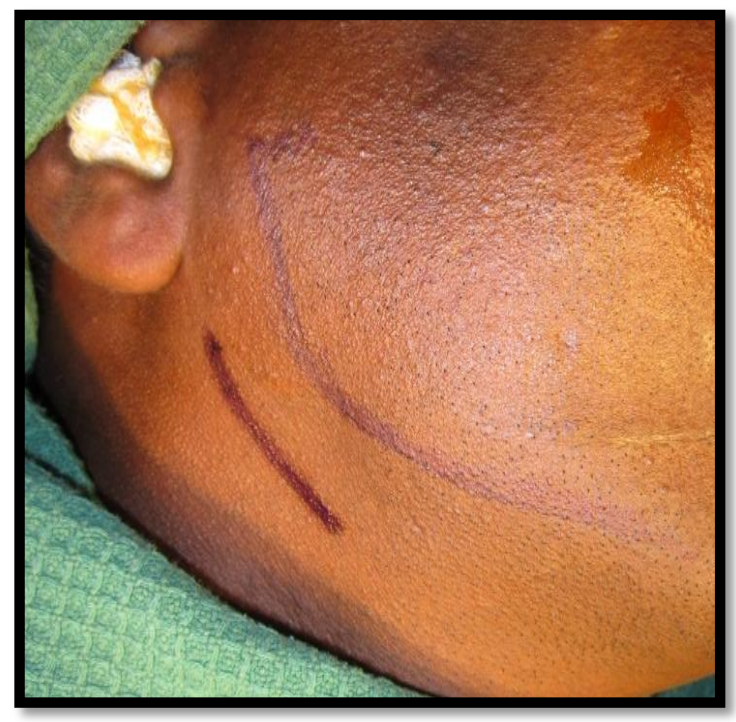

Fig-3: shows Retromandibular incision

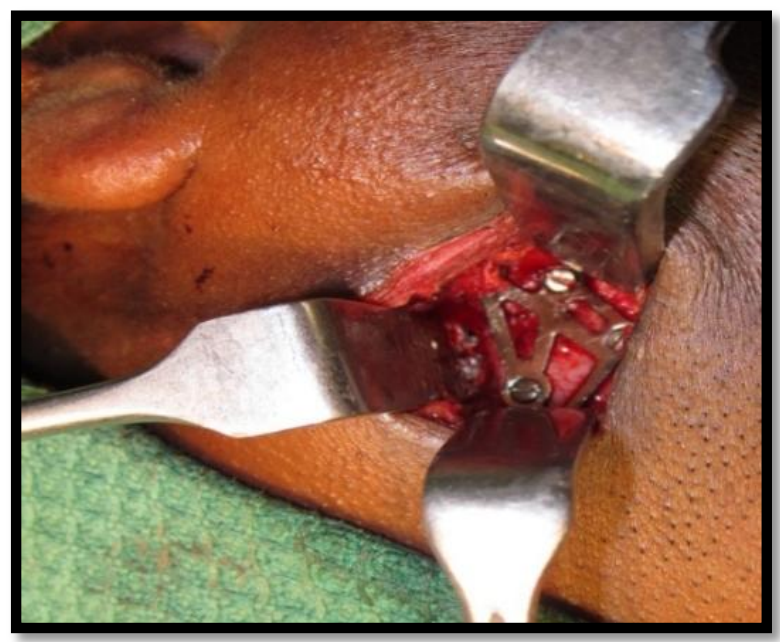

Fig-4: shows Strut plating

Four patients underwent postoperative intermaxillary fixation for a period of one week and an extended duration of up to 6 weeks. This was done in patients with bilateral condylar fracture whereas a high condylar fracture case was conservatively managed. Postoperative edema and swelling were minimal with no incidence of wound infection. Weakness of the temporal branch of facial nerve was noted in one of the patients in whom frontotemporal incision was performed. Postoperative radiograph (fig.5) was taken to check the reduction of fracture segments and followup was done for a period of 6 months to 1year.

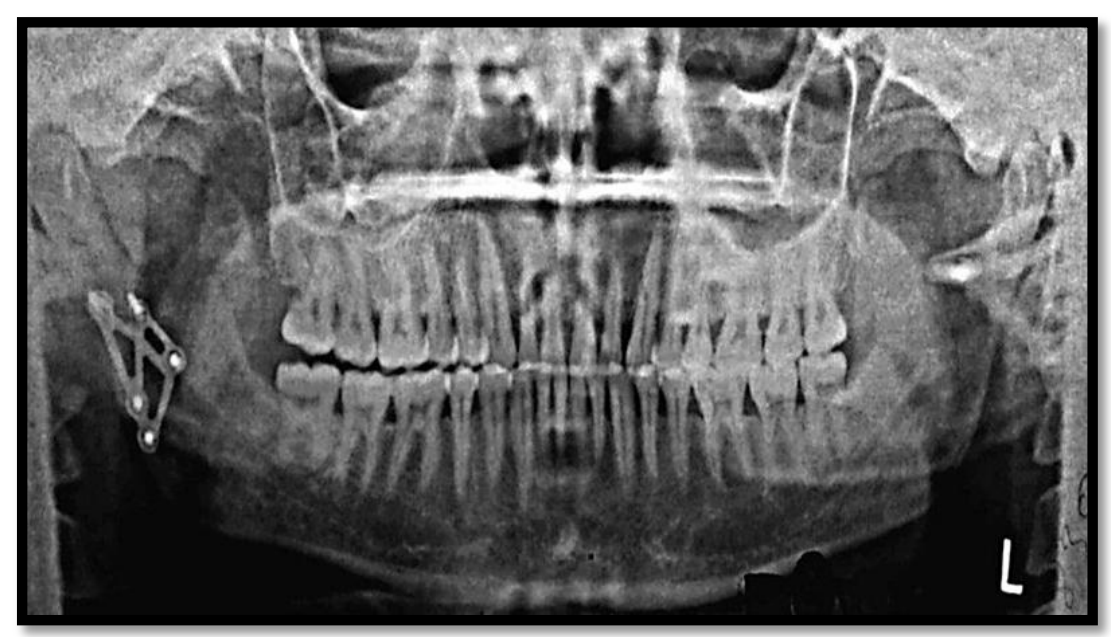

Fig-5: Shows Post-operative OPG 
RESULTS

Table-1: Summarizes the details of the patients and the surgical approach used in the study. The mean age of patients was 32 with SD 4.0.

\begin{tabular}{|c|c|c|c|c|c|}
\hline SUBJECTS & SEX & AGE & $\begin{array}{c}\text { LOCATION OF } \\
\text { FRACTURE }\end{array}$ & $\begin{array}{c}\text { SURGICAL } \\
\text { APPROACH }\end{array}$ & PLATES \\
\hline 1 & $\mathrm{M}$ & 30 & L-Subcondyle & $\begin{array}{c}\text { Retromandibular } \\
\text { Vestibular incision }\end{array}$ & $\begin{array}{c}5 \text { hole STRUT } \\
\text { 4 hole SS plate }\end{array}$ \\
\hline 2 & $\mathrm{M}$ & 36 & L-Subcondyle & $\begin{array}{c}\text { Retromandibular } \\
\text { External laceration }\end{array}$ & $\begin{array}{c}5 \text { hole STRUT } \\
\text { 4 hole SS plate }\end{array}$ \\
\hline 3 & $\mathrm{M}$ & 36 & R-Subcondyle & Retromandibular & 5 hole STRUT \\
\hline 4 & $\mathrm{M}$ & 34 & R-Subcondyle & $\begin{array}{c}\text { Retromandibular } \\
\text { Vestibular incision }\end{array}$ & $\begin{array}{c}5 \text { hole STRUT } \\
\text { 4 hole SS plate }\end{array}$ \\
\hline 5 & $\mathrm{M}$ & 30 & L-Subcondyle & $\begin{array}{c}\text { Retromandibular } \\
\text { Vestibular incision }\end{array}$ & $\begin{array}{c}5 \text { hole STRUT } \\
\text { 4 hole SS plate }\end{array}$ \\
\hline 6 & $\mathrm{M}$ & 26 & L-Subcondyle & $\begin{array}{c}\text { Frontotemporal } \\
\text { Retromandibular }\end{array}$ & $\begin{array}{c}5 \text { hole STRUT } \\
\text { 4 hole SS plate } \\
\text { 3nos orbital plates }\end{array}$ \\
\hline
\end{tabular}

Table 1 shows Characteristics of patients and surgical procedure done

Table-2: summarizes additional fractures, occlusion, complications of all the patients from preoperative to $6 \mathrm{months}$. The mean of additional fractures, occlusion and complications was 3.50 between preoperative and 2 months follow-up. The mean between preoperative and 6months follow-up was 3.50and follow-up of 2 months to 6 months was 2.50 . A significant difference in terms of additional fractures, occlusion and complications were found $(P$-value $<0.02$ to 0.059$)$.

\begin{tabular}{|l|r|r|r|}
\hline OCCLUSION, ADDITIONAL & PRE-OP - & \multicolumn{1}{c|}{ PRE-OP - } & $\begin{array}{l}\text { 2MONTHS - } \\
\text { FRACTURES AND COMPLICATIONS }\end{array}$ \\
\hline 2MONTHS & 6MONTHS & 6MONTHS \\
\hline Asymp. Sig. (2-tailed) & $-2.226^{\mathrm{b}}$ & $-2.201^{\mathrm{b}}$ & $-1.890^{\mathrm{b}}$ \\
\hline
\end{tabular}

Table 2 shows Additional fractures, Occlusion and Complications between preoperative to 6months.

Table-3: Summarizes the mouth opening of study subjects according to preoperative, 2months and 6months follow-up with significant differences $(P$-value $<0.004)$ between the follow-up of the subjects.

\begin{tabular}{|c|c|c|c|c|}
\hline $\begin{array}{l}\text { MOUTH } \\
\text { OPENING }\end{array}$ & $\mathbf{N}$ & MEAN & $\begin{array}{c}\text { STD. } \\
\text { DEVIATION }\end{array}$ & $\begin{array}{l}\text { P-VALUE } \\
\text { ASYMP.SIG }\end{array}$ \\
\hline PRE-OP & 6 & 33.3333 & 3.07679 & \\
\hline 2MONTHS & 6 & 37.6667 & 2.65832 & $<0.004$ \\
\hline 6MONTHS & 6 & 40.0000 & 1.26491 & \\
\hline
\end{tabular}

Table 3 shows mouth opening of study subjects between Preoperative to 6months.

\section{DISCUSSION}

The treatment methods for condylar fractures remains controversial. Non-surgical approach is the commonly employed treatment option for condylar fractures in children, whereas surgical versus nonsurgical management of the same in adults still remains controversial [6]. Two open reduction techniques; rigid internal fixation (RIF) and adaptive mini plate fixation, have replaced the use of wire osteosynthesis and prolonged maxillomandibular fixation (MMF) [7].

Today, various approaches to condyle have been used and described in literature. The advantages of retromandibular approach over other approaches include: shorter working distance from the skin, incisions to the condyle, greater access to the posterior border of the mandible and sigmoid notch, little risk of facial nerve damage, less conspicuous facial scar and easy reduction [8]. There are various plates and plating systems available, in which the 3D Strut plating system provides an adequate tensile stress pattern at the condylar neck region with less complication and an easy surgical approach.

In our study, surgical methods such as open reduction and osteosynthesis with $3 \mathrm{D}$ mini plates, wires or lag screws were used. After open reduction procedure, the IMF was placed. IMF allows fractured segments to be in place. Single mini plates can be adequate if the fragments are aligned properly, but when functional forces exceed the rigidity of one mini plate, the use of two has been proposed. The majority of simple, displaced or minimally displaced fractures of the condylar and sub condylar regions can be adequately treated by osteosynthesis with 1 or 2 mini plates [9]. There are biomechanical and clinical studies suggesting that the 2 mini plate fixation techniques 
provide functionally stable fixation for fractures of the mandibular condyle [10]. However, in the condylar neck, the amount of bone is not always adequate to permit placement of 2-3 screws per fragment. It also includes the use of excess armamentarium and increased exposure of the condylar region. Therefore, mini plates and modifications in mini plates based on Champy's principle like titanium 3D plating system have been developed to meet the requirements of semirigid fixation with lesser complications. The basic concept of 3D fixation as explained by Farmand is that a geometrically closed quadrangular plate secured with bone screws creates stability in three dimensions. The $3 \mathrm{D}$ mini plates are a misnomer as the plates are not three dimensional but hold the fracture fragments rigidly by resisting the forces in three dimensions, namely shearing, bending and torsion forces [5].

The 3D plating system has a compact design and is easy to use [11]. Titanium is the metal of choice for fixation plates mainly because of its high biocompatibility and ease of manipulation. The strut shape provides three-dimensional stability in open reduction and internal fixation of mandibular subcondylar fractures. Tensile strains occur mainly at the anterior and lateral borders of the condyle and compressive strains, at the posterior and medial borders. In our study, the lowest incidence of postoperative complications were reported when compared with previously reported articles in the literature. However, in our study, only one patient had a transient paralysis of facial nerve who was also later treated for the condition. All the patients in our study had a normal mouth opening $(36 \mathrm{~mm}-42 \mathrm{~mm})$ by the third month. Postoperative radiographic evaluation revealed the stability of osteosynthesis of the $3 \mathrm{D}$ strut plate by the end of $3^{\text {rd }}$ month.

Our study had merits and demerits. Using the new strut-shaped plate for condylar neck fractures had two advantages, namely neutralization of changing strains at the anterior, lateral, and posterior borders; also providing additional stabilization. The Strut plating system can transmit demanded loads in all directions of movement. This plate allows a functionally stable osteosynthesis in the condylar neck region of the mandible. Even though this strut-shaped plate has lots of merits, it has certain drawbacks. Adaptation of the strut plate in the mandibular condylar region is a challenging task for the surgeon, with its longest dimension of $28 \mathrm{~mm}$.

\section{CONCLUSION}

3D strut plate can be used in subcondylar fractures with surgical ease, adequate stability and functional outcome. Furthermore, studies with a larger sample size have to be performed to validate our study in the future.

\section{REFERENCES}

1. Silvennoinen, U., Iizuka, T., Lindqvist, C., \& Oikarinen, K. (1992). Different patterns of condylar fractures: an analysis of 382 patients in a 3 -year period. Journal of oral and maxillofacial surgery, 50(10), 1032-1037.

2. Singh, G., Mohammad, S., Das, S., Passi, D., Vishwakarma, K., \& Mahajan, N. (2013). Trapezoidal condylar plate: report of 15 cases in the management of mandibular subcondylar fracture. J Adv Med Dent Sci, 1(2), 13-18.

3. Handschel, J., Rüggeberg, T., Depprich, R., Schwarz, F., Meyer, U., Kübler, N. R., \& Naujoks, C. (2012). Comparison of various approaches for the treatment of fractures of the mandibular condylar process. Journal of Cranio-Maxillofacial Surgery, 40(8), e397-e401.

4. Brandt, M. T., \& Haug, R. H. (2003). Open versus closed reduction of adult mandibular condyle fractures: a review of the literature regarding the evolution of current thoughts on management1. Journal of oral and maxillofacial surgery, 61(11), 1324-1332.

5. Chaudhary, M., Pant, H., Singh, M., Vashistha, A., \& Kaur, G. (2015). Evaluation of trapezoidalshaped 3-D plates for internal fixation of mandibular subcondylar fractures in adults. Journal of oral biology and craniofacial research,5(3), 134-139.

6. Ellis III, E., \& Throckmorton, G. S. (2005). Treatment of mandibular condylar process fractures: biological considerations. Journal of oral and maxillofacial surgery, 63(1), 115-134.

7. Haug, R. H., \& Assael, L. A. (2001). Outcomes of open versus closed treatment of mandibular subcondylar fractures. Journal of oral and maxillofacial surgery, 59(4), 370-375.

8. Narayanan, V. I. N. O. D., Kannan, R., \& Sreekumar, K. (2009). Retromandibular approach for reduction and fixation of mandibular condylar fractures: a clinical experience. International journal of oral and maxillofacial surgery, 38(8), 835-839.

9. Sugiura, T., Yamamoto, K., Murakami, K., \& Sugimura, M. (2001). A comparative evaluation of osteosynthesis with lag screws, miniplates, or Kirschner wires for mandibular condylar process fractures. Journal of oral and maxillofacial surgery, 59(10), 1161-1168.

10. Rowe, N. L., \& Williams, J. L. (1985). Maxillofacial injuries. Churchill Livingstone.

11. Malhotra, K., Sharma, A., Giraddi, G., \& Shahi, A. K. (2012). Versatility of titanium 3D plate in comparison with conventional titanium miniplate fixation for the management of mandibular fracture. Journal of maxillofacial and oral surgery, 11(3), 284-290. 